\title{
Liquid Golds
}

\section{THE PRODUCTS AND THEIR APPLICATIONS}

\author{
Aram N. Papazian \\ Engelhard Industries Division, Engelhard Corporation, East Newark, N.J., U.S.A.
}

\begin{abstract}
Gold in the form of leaf or powder bas long been used for the decoration of ceramic ware. The development of liquid golds in the early 1830's, however, made it possible for craftsmen to carry out such decoration more simply and economically. This technological breakthrough led not only to the widespread use of gold on ceramic and glass, but also, in more recent years, to sophisticated applications in areas such as the aerospace and electronics industries.
\end{abstract}

A 'liquid bright gold' is a preparation which, when applied to a smooth glossy surface, usually ceramic or glass, and heated in air to burn off organic constituents, produces a specular or mirror-like film of gold. This film is of at least 22 carat gold and usually about $125 \mathrm{~nm}$ thick.

Other products, called lustres, are based upon the same technology. Dilute formulations of liquid bright golds produce attractive transparent red, violet, blue, ruby, pink or green hues, and are used in similar fashion by glass and ceramic decorators to produce articles of beauty.

Liquid bright golds are basically solutions in organic solvents of organic compounds in which a gold atom is attached to a sulphur or oxygen atom which in turn is linked to a carbon atom. They contain small, but essential, additions of compounds of rhodium and of base metals such as bismuth, chromium, vanadium, silicon and tin. The rhodium ensures that the gold film which forms on the substrate on firing is bright. Its sesquioxide, $\mathrm{Rh}_{2} \mathrm{O}_{3}$, is apparently formed on the grain boundaries of the gold particles, thereby preventing agglomeration by diffusion of gold from one particle to another when they are in contact. As a result, growth in the size of these particles, which could lead to the formation of gold islands on the surface of the substrate, is inhibited (1). The base metals ensure reaction bonding of the gold film to the substrate (2). When organic compounds of gold without the addition of rhodium and base metals are applied to refractory surfaces and heated, useless, nonadherent deposits of discrete particles of gold are produced.

Fig, 1 Dissolving of gold granules is the beginning of the liquid gold production process

\section{The Industry}

The earliest manufacture of liquid bright gold is credited to Heinrich Gottlob Kühn (3), first a technical manager and then director of the Royal Porcelain Factory at Meissen, in Saxony. The process was kept secret until 1851, when the Deutertre brothers patented their method of manufacture. Within a decade of the patent grant, the Deutertre company was said to be consuming $4 \mathrm{~kg}$ of gold each month (3).

In 1879, Degussa (4) started up a liquid bright gold production plant in Frankfurt, Germany. Soon afterwards, the firm assigned its technology to Johnson Matthey for use in Great Britain, China and Japan.

Liquid bright gold was first produced in the U.S.A. by the Roessler and Hasslacher Chemical Company, established in New York in 1882. This firm was later acquired by E.I. du Pont de Nemours and Company which produced a variety of decorative gold preparations until the early 1970's, when this activity was discontinued. At that time, the major

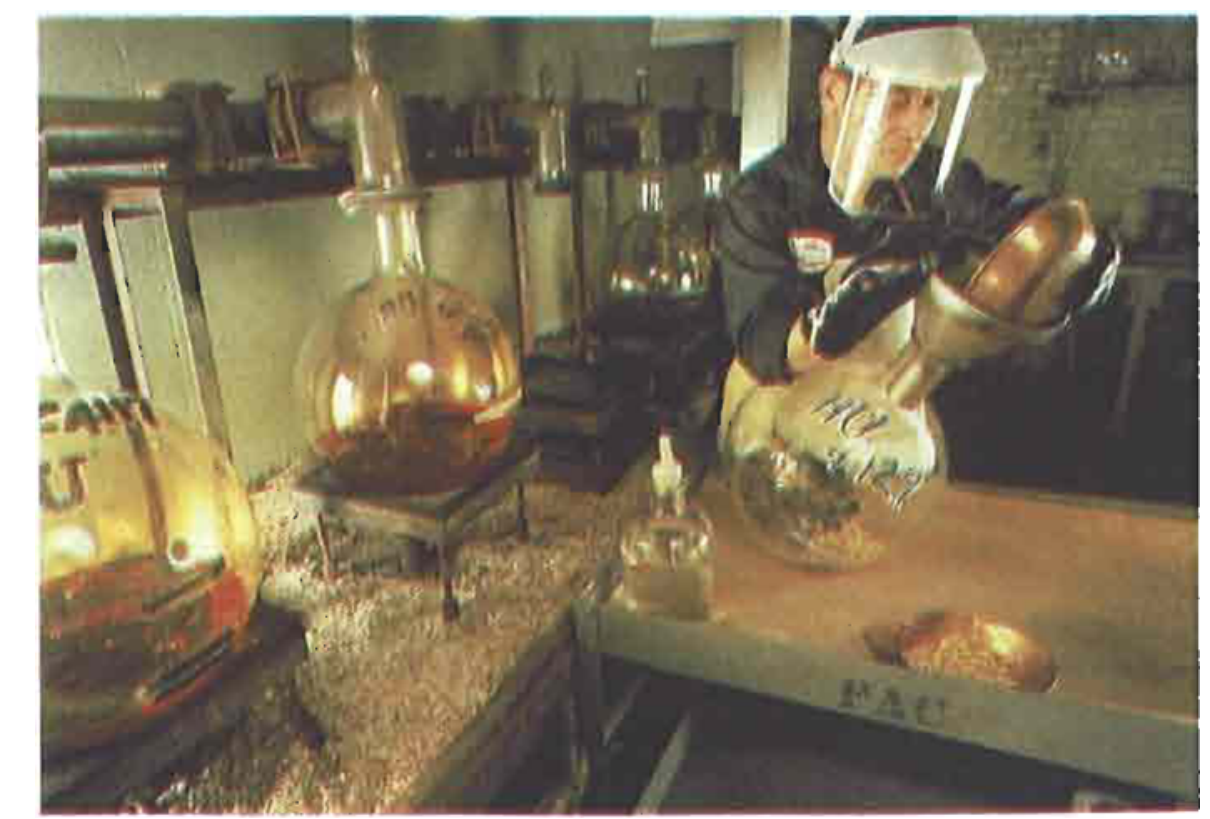


manufacturer of liquid bright golds was the Hanovia Liquid Gold Department of Engelhard Industries, a world-wide precious metal processing firm. Hanovia's origins date back to 1905 when Charles W. Engelhard formed the Hanovia Chemical and Manufacturing Company to produce liquid bright golds and other preparations for the decoration of glass and ceramic for the American market. Today, Engelhard Corporation's Hanovia operation continues to be the leading manufacturer of liquid golds in the U.S.A. and has production facilities also in Italy, England and Japan.

In the era when Meissen was the centre for producing decorative porcelain objects, competition among the manufacturers was so keen that technological advances were closely held secrets. Little was published until 1927 when Chemnitius (5) described how gold chloride mixed with sulphurized terpene reacts to produce a gold terpene sulphide which is soluble in a wide range of organic solvents and essential oils. Prior to 1950 , this class of gold-containing organic compounds was the main ingredient in liquid bright golds.

In 1949, Ballard (6) disclosed the use of cyclic gold terpene mercaptides for liquid bright gold manufacture. More recently, Fitch (7) patented a series of gold tertiary mercaptides for use in liquid bright golds. These newer organic compounds are characterized by their higher gold content of 20 to 60 per cent by weight, greater solubility in a larger variety of solvents and lower thermal decomposition temperatures. Such properties have led to markedly improved products.

The objects decorated with liquid gold preparations range from simple inexpensive ashtrays, glass containers and tableware to richly decorated lamp bases and fine china. The preparations are used in most countries, and throughout the world there are manufacturers of liquid bright golds to supply the decorators' demand. Engelhard Corporation/Hanovia, Degussa and Johnson Matthey play the more prominent roles. However, there are local producers in Italy, France, Japan, the Soviet Union, Mexico, Brazil and Argentina, who serve these markets. It is estimated that more than 10 tons of gold is annually processed world-wide into products for application on glass and ceramic ware. While this quantity is not as large as those for jewellery, dentistry or electronics, it is nevertheless significant and reflects a continuing consumer demand for gilded glass and ceramic products.

\section{Early Products}

During its 150-year history, liquid bright gold technology, like any other that has survived such a span of time, has undergone constant improvements to meet changing commercial needs.

The first preparations were limited to simple liquids used by the artisan to decorate various ceramic objects, by application with a brush. Inconsistent product quality was the tule, but was compensated for by the experience and skill of the user. Thus, variations in viscosity from batch to batch were considered unavoidable and each decorator prided himself on his ability to make adjustments to his liking, either by thinning or evaporation. Work benches were miniature chemistry laboratories with jars and bottles of essences, oils and organic solvents.

The firing process which converts the brown liquid deposit into a specular clean gold film is critical. Earlier formulations containing natural resinous materials of unknown or inconsistent quality were particularly sensitive to inappropriate firing conditions. Less-than-specular, dull, scummed or discoloured gold films of unacceptable quality resulted if furnace temperatures and atmospheres were not carefully controlled. Fired film quality was also affected by the thickness of the liquid gold application. Over-application caused blistering and dullness, while under-application resulted in weakness of the gold colour.

Clearly, most of these difficulties were caused by variations in the quality of the natural ingredients used for the preparation of liquid golds.

Liquid golds were initially formulated for use only on ceramics. Products for glass came later and required a separate development effort. The variety of glasses and the lower maximum temperatures to which they may be submitted during firing made early liquid golds unsuitable for use on them. The major stimulus for the development of preparations applicable to glass has arisen in the U.S.A. over the past 40 years, because of increased demand for decorated glassware.

Adhesion of the fired gold film, which directly influences its utility, left much to be desired with earlier products. The property became especially relevant with the introduction of the dishwasher, in which strong detergents are used. It is an important consideration also for decorative labelling of cosmetic, liquor and other commercial containers.

The firing temperatures of the products of yesteryear were in excess of $550^{\circ} \mathrm{C}$. As time progressed, however, liquid golds were required which would mature quickly at lower temperatures and so be applicable to an increasing variety of substrates in decorative and industrial applications. This demand for more versatile, liquid bright golds of high performance became particularly pressing from 1950. The challenge was to be met successfully by the industry.

\section{Modern Advances}

The variety and quality of liquid golds offered today bear testimony to the advances made by manufacturers during the last three decades. 
As recently as 1940 , liquid golds were supplied primarily with a pain consistency. Since then, automatic machine application (up to 100 pieces per minute) has fostered the development of liquid golds in forms that range from very thin liquids to viscous pastes. Almost without exception, the advances made in recent years have resulted from the need to satisfy requests by users of liquid golds.

A typical liquid bright gold may consist of as many as forty or more separate ingredients. As recently as 15 years ago, raw material inventories consisted of such items as balsams (derived from saps from evergreens), lavender and other natural essential oils, natural resins, asphalt and turpentine. While some of these natural products are still in use, synthetic materials have been the key to the development of many new liquid golds. Synthetic resins and essential oils, organic acids and commercially available organic compounds of base metals have partially replaced the traditional raw materials with the result that liquid golds of more consistent and improved quality are now produced.

With the proliferation of liquid gold forms, the control of their physical properties became increasingly important, and in fact critical, to ensure reproducible performance. Perhaps the most significant property, viscosity (or more properly, rheology), could not be accurately measured until the development in recent years of suitable instruments, which greatly assist the characterization of liquid golds. One such instrument was the Shirley Ferranti viscometer which has served the industry most effectively for new product development and production control. Measurements made by this instrument can be related to the behaviour of liquid golds in production processes and provide a means of establishing quality control parameters.

The widening of the range of substrates to be decorated, from glazed ceramics to a variety of glasses, confronted the liquid gold manufacturer with another challenge, namely the compatibility of liquid golds with these substrates. Liquid golds had to be developed for use at different maturing temperatures and on new substrate compositions. Thus, leadrich glasses require golds that mature at temperatures as low as $500^{\circ} \mathrm{C}$, while lead borosilicate glasses require firing to $650^{\circ} \mathrm{C}$, and soda-lime glasses, the most common, require a product that matures at $600^{\circ} \mathrm{C}$. Ceramic substrates, on the other hand, require liquid golds that may be fired in the temperature range of 700 to $900^{\circ} \mathrm{C}$.

Significant technological advances were the improvements in the durability of gold films obtained from liquid gold preparations, and in their adhesion to glass. The necessity for these arose from the damaging effect of domestic dishwashers on gilded tableware. (It is generally considered that a single dishwasher cycle equals over a hundred hand washings.)

The rising price of gold has affected liquid gold manufacturers to the extent of endangering their very existence. The price of gold has varied between 35 and 800 U.S.\$/oz. since the beginning of the 1970's. Fortunately, the industry reacted to this problem at an early stage and sought means to counter it through the development of compositions requiring less gold and permitting more efficient use of the metal.

The average gold content of liquid golds prior to the period of gold price increase was 10 to 11 per cent by weight, and a major effort was made to lower this level while still offering a quality product. Currently, preparations containing commonly between 6 and 8 per cent gold, or sometimes as little as 4 per cent, are being used successfully by decorators. While these reductions do not fully compensate for the rise in the price of gold, they have done much to salvage the usage of liquid golds and to restrict market losses mostly to economically marginal uses.

A final example of the ingenuity applied by manufacturers to meeting the needs of a changing market is the formulation of liquid golds in thermoplastic form. With the development of high-speed decorating machinery and demand for multicoloured designs, the need for this new, unique form of 'liquid' gold arose. The product is waxlike and solid at room temperature. When applied through an electrically heated metal screen, it produces a dry gold-containing deposit which resists smearing during handling prior to firing. This development met yet another requirement of the decorator and further broadened the applications for liquid golds.

One characteristic of the industry which has remained, however, is the secrecy surrounding new formulations, although the development of sophisticated analytical instruments and techniques has made this increasingly difficult to maintain.

\section{Methods of Application}

The users of liquid golds may apply them by any of a variety of proprietary methods and techniques. This aspect of the industry explains the development of hundreds of liquid gold formulations.

The original method of application, that of manually brushing, much as an artist would, is still utilized. Typically, a hand decorator employs a turntable on which the object to be decorated is placed, along with a supply of artist's brushes in a range of sizes and shapes, and a well and plate on which he maintains his working supply of liquid gold. While the technique is relatively slow and results depend largely upon the skills of the decorator, modern formulations have minimized the risks of failure by allowing the user a wider margin for variation.

Since 1950, the technique of applying liquid golds by screen printing has increased significantly in popularity, 


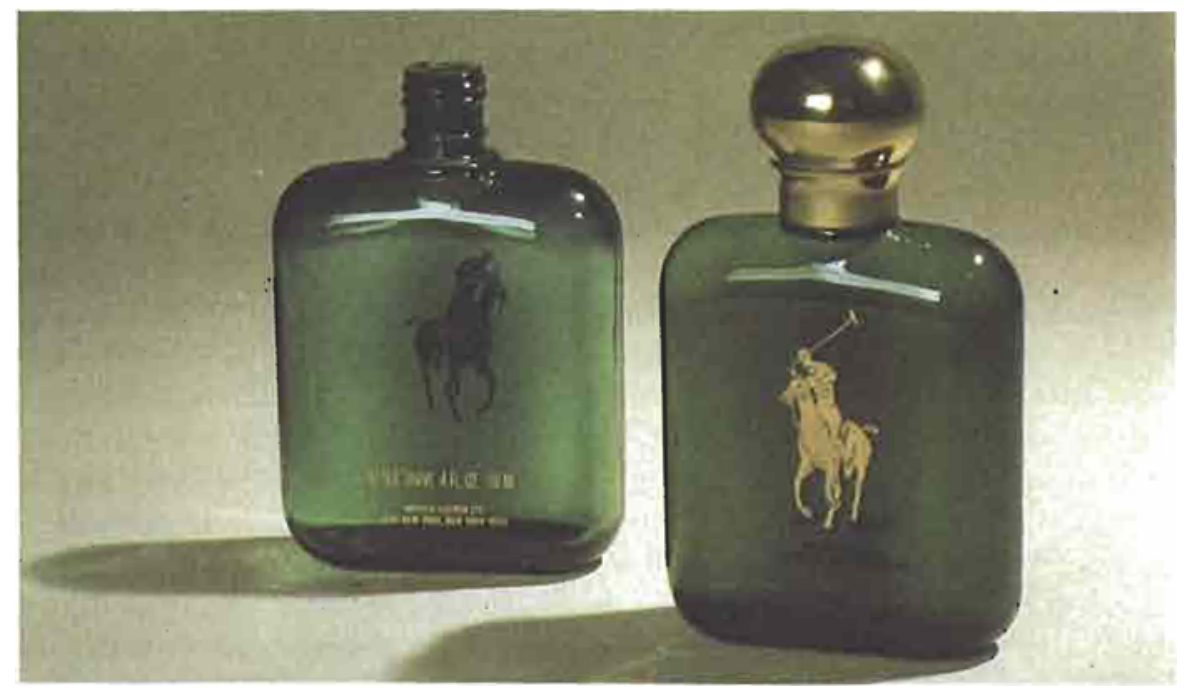

Fig. 2 This gold decorated glass container for men's fragrance has received wide acclaim for excellence in package design. This cosmetic package is produced by applying liquid bright gold using a screening method

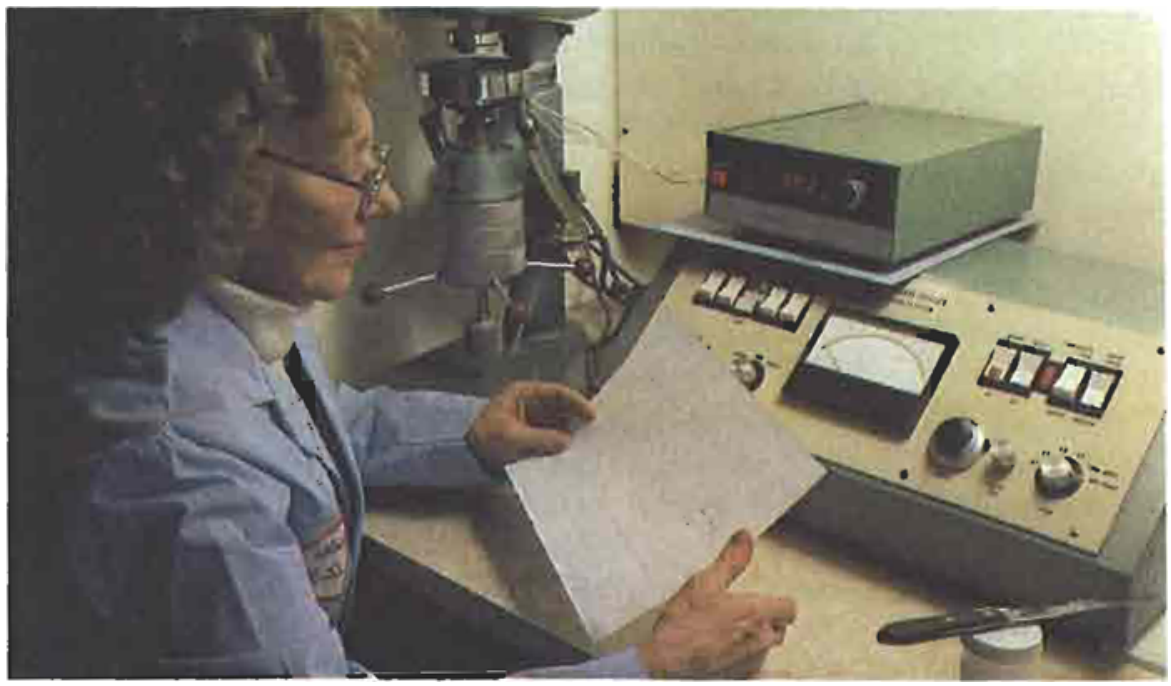

Fig. 3 Shirley Ferranti viscometer used to determine the viscosity of liquid bright gold by antomatically plotting data from which rheological properties can be calculated

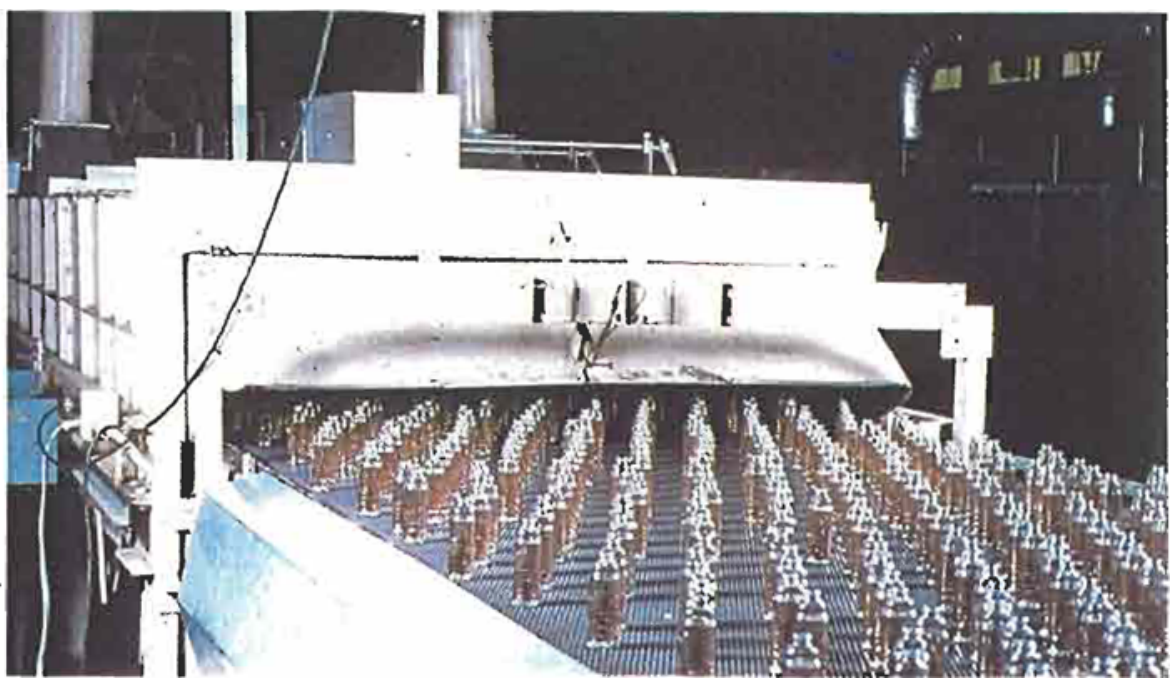

Fig. 4 Gold decorated glass perfume bottles after firing in a lehr (glass annealing) furnace 
especially in the U.S.A. where glass tableware and container decorating has grown rapidly. Generally referred to as 'squeegee' bright golds, the products used in this technique account for the major use of liquid golds in that market. The success of screen printing is due to its versatility. Intricate designs and finely detailed gold decors may be produced at rates which range from deliberate slow manual application to 100 prints per minute with automatic high-speed machines. Cylindrical, flat and even tapered sufaces can be conveniently decorated. The process employs a flexible plastic or rubber blade to force liquid gold with the consistency of a paste through a fine stencil or screen onto the surface being decorated. Screens are made of 200 to 400 mesh fabric, most commonly of monofilament nylon or polyester. They are prepared by stretching the fabric taut on a frame and developing onto it the pattern or artwork, utilizing a photographic process.

Screen printing is commonly employed for the application of ceramic colours and electronic inks, for the decoration of poster and sign parts or to mark metal and plastic containers with appropriate paints.

Decorators have found spraying to be a convenient technique for applying liquid golds where overall or undefined areas are to be decorated. Preparations for this purpose are formulated in a thin, water-like consistency which must conform to tight specifications for levelling, wetting and drying, to ensure successful use.

'Machine banding' golds form yet another family of products that has been developed for a specific method of application. Machine banding replaces costly hand application of gold bands on mass-produced items. Many machines have been developed by equipment manufacturers and the larger glass and ceramic decorators, which automatically, rapidly and efficiently apply these decors. Innovative tooling and machine design are used to accommodate the various shapes of decorated wares. The patterns are usually limited to single or concentric bands, up to $13 \mathrm{~mm}$ wide, which are applied on the edges and accessible areas of the glass or ceramic item being decorated. Liquid golds for machine banding are moderately viscous, tacky and tend to be 'stringy'. They are slow-drying to maintain their working properties during prolonged exposure on machine parts. Banding golds can be applied more thinly than formulations for other techniques and therefore require higher gold contents to produce decors of acceptable quality. It is common to use a preparation with a gold content of 16 to 18 per cent by weight to produce a result equivalent to that achieved by a 10 per cent hand applied or screen-printed liquid gold.

Machine banding is employed to economic advantage mostly by fine china and ceramic tableware manufacturers.
A more recently developed process is silicone pad printing. Liquid golds have been successfully adapted to this method of applying intricate patterns onto objects of complex shapes. An automatic machine process, it consists of blading liquid gold onto a steel plate on which a design has been etched, scraping off the excess to leave liquid gold only in the etched depression, pressing a flexible silicone pad onto the plate to pick up the liquid gold and finally impressing the silicone pad on the object being decorated.

Again, in the case of silicone pad printing the challenge to the liquid gold maufacturer was the development of a product useful for an increasingly popular method. A new class of liquid golds having special physical properties had to be developed. These had to accommodate the major limitation of the process, namely that only a very thin film of liquid gold can be printed. Compensation was made for this by using products with higher gold content.

The methods of application of liquid golds are not restricted to those reviewed above. Rubber stamping, roller coating, water flotation, veiling, stippling, decal transferring, dipping, spin coating and other techniques too are or have been successfully employed. It is therefore not surprising to find that the major manufacturers maintain files containing specifications for literally hundreds of liquid gold formulations to which they regularly add as new requirements are presented to them.

\section{Decorative Uses}

It is essential here to discuss briefly the economics of liquid golds.

Many consumers, and even some users, have misconceptions concerning the nature of the film produced from liquid golds. Since the result of firing is essentially a deposit of approximately 22 carat gold, a frequent conclusion is that the use of liquid golds is very expensive. Obviously, it is more costly today than when gold was 35 U.S.\$./oz., but once it is realized that the matured film is only about $125 \mathrm{~nm}$ thick, the true economic picture becomes more apparent. Thus, $100 \mathrm{~g}$ of liquid gold, containing $10 \mathrm{~g}$ of gold, can coat up to $5 \mathrm{~m}^{2}$ of surface. Using 500 U.S. $\$ / \mathrm{oz}$. as the price of the metal, the material cost for decorating a square centimetre of area is much less than one cent, irrespective of the quality of liquid gold used.

Contemporary uses of liquid golds are primarily for the decoration of ceramic and glass. The major manufacturers of these wares maintain large decorating departments or use independent decorators engaged in the speciality business of applying liquid golds.

The decors may range from simple bands on the edges of ceramic tableware to lavish designs on glass tumblers. Moreover, gold is commonly used in combination with 


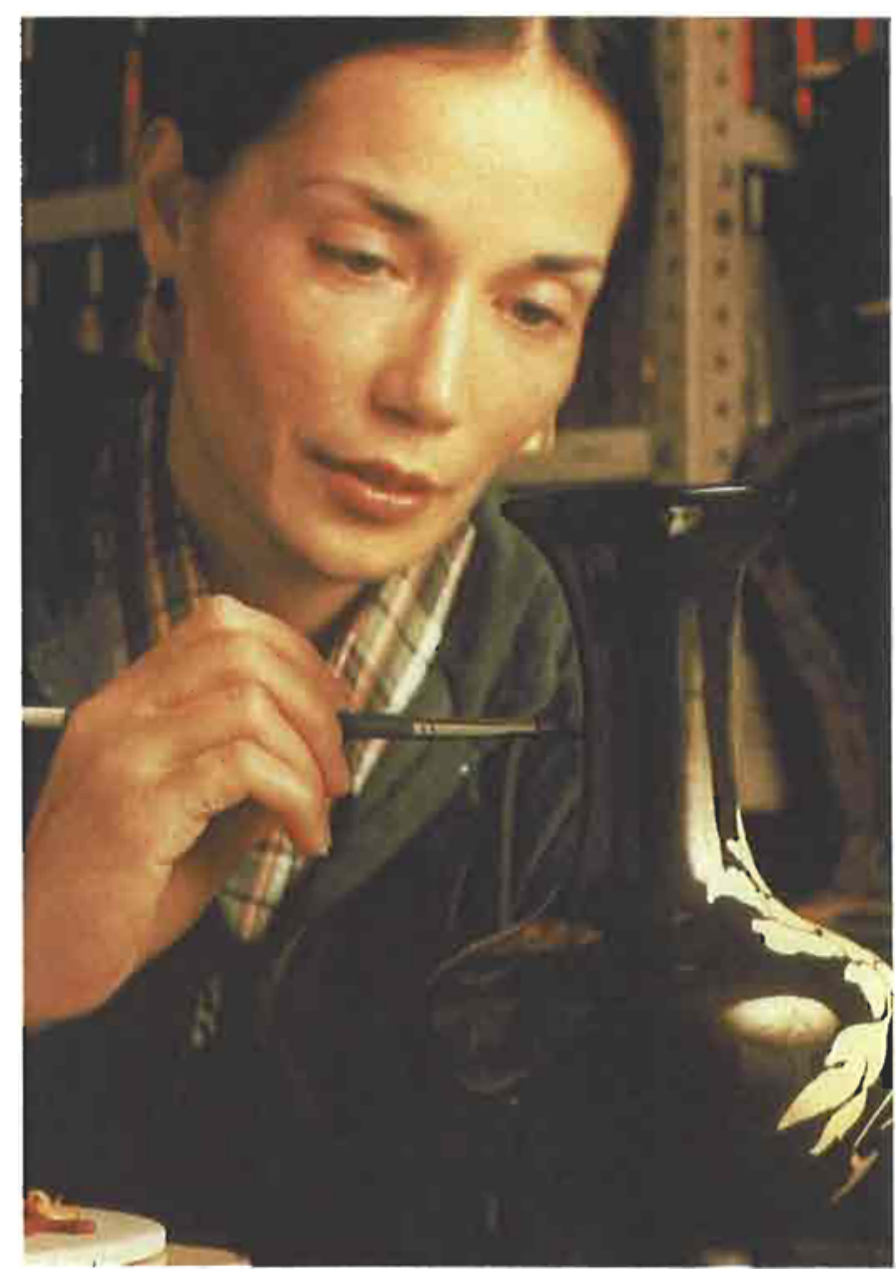

Fig. 5 Brushing liquid bright gold on to ceramic artwork ceramic colours to produce multi-coloured effects. If it is applied over a ceramic colour, a raised or relief effect is achieved, while if it is applied over a dull or frosted finish, a rich golden, satin effect is produced. As many as five or six colours are often used in combination with liquid gold to produce elaborately decorated items.

Glass and ceramic packaging makes effective use of liquid golds. For many years, the cosmetic industry has recognized the elegance and appeal of gold for the labels of its products. The liquor industry too, has found the use of containers richly decorated with gold to be an effective promotional tool in the sale of special gift packages.

The flat glass decorating segment is still another area of the industry in which liquid golds are successfully used - on panels, clock faces, furniture glass, novelty and giftware. Specific examples are gold lettering, numerals and designs on glass panels for appliances.

Further afield, genuine gold imparts elegance to architectural design. Thus, liquid gold is employed to produce distinctive effects on ceramic tiles and other building materials, glazed brick, enamelled steel and structural glass. Gold-decorated components can be utilized for building facades, roofs and windows, and for store fronts, signs and emblems. Interior components decorated with liquid gold provide the architect with the means to design practically and at a limited cost - with a luxurious look. The noble character of the gold finish affords long lasting beauty, for it remains bright and spectacular for the life of a building. The Richfield Building constructed in Los Angeles in 1929 with a ceramic veneer finished with liquid gold stood unmarked for over thirty years until it was demolished.

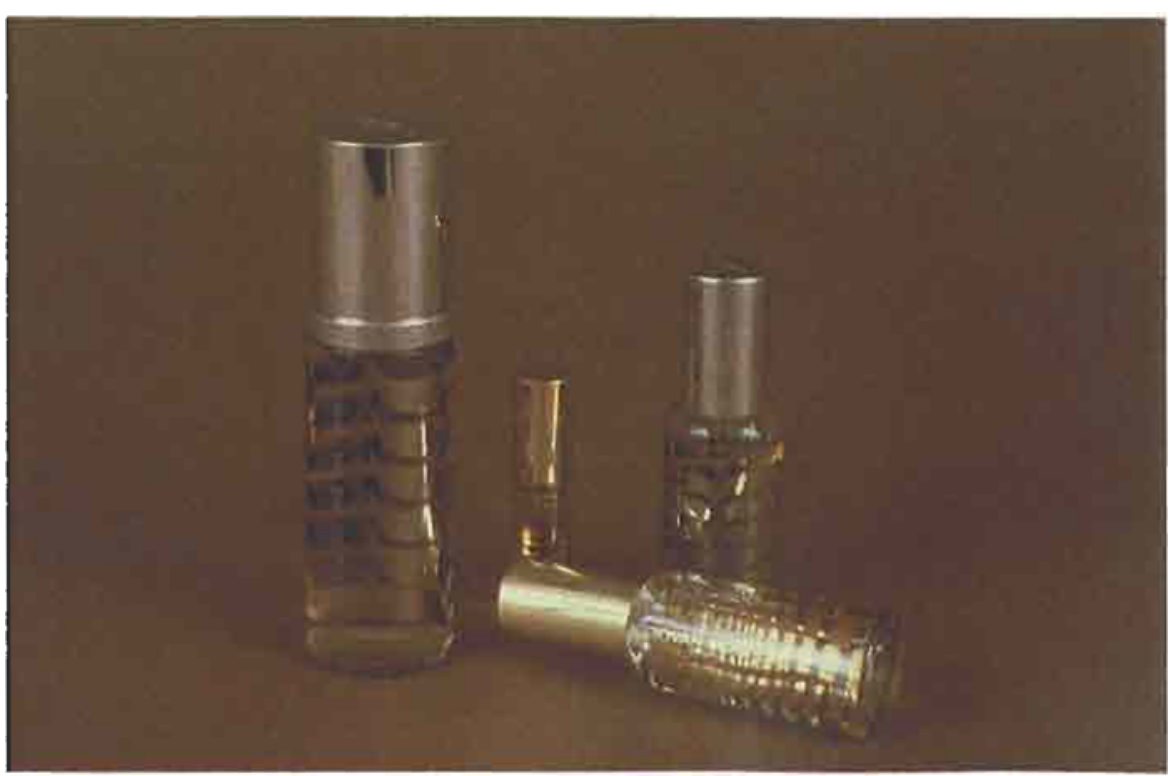

Fig. 6 Perfume bottles decorated with liquid bright gold exemplify the elegance and appeal of gold in cosmetics container labelling 


\section{Functional Uses}

The applications of liquid golds are not limited to the decorative field. The property of gold as an efficient reflector of infrared radiation is retained by the thin films produced from liquid golds. Their resistance to high temperatures, flexibility of application, costeffectiveness and mass advantage have led to many applications of liquid gold for temperature control.

Liquid golds have been successfully applied for heat reflection on aluminium, magnesium, titanium, on base metal alloys such as stainless steels, on enamelled steel, on asbestos board, polyamide films and other materials which can be fired to $230^{\circ} \mathrm{C}$, or more, without decomposition.

Thin, and therefore lightweight, liquid gold coatings are ideal to reduce heat transmission on aircraft engine shrouds, drag parachute containers, tailcone assemblies, blast shields, ducts and tubing. Similarly, use is made of liquid golds to protect heatsensitive parts in space vehicles from solar radiation.

The effectiveness of gold for temperature control stems from its high reflectivity of radiation in the wavelength range of 0.2 to $15 \mu \mathrm{m}$ (Table I), and its very low emissivity value of 0.05 . Compared to a perfect black body having an emissivity value of 1.0, one can theoretically expect a gold film to radiate only 5 per cent of the energy radiated by the former.
Table 1

Infrared Radiation Reflectance of Liquid Bright Gold Film

\begin{tabular}{|c|c|c|c|c|c|c|c|c|c|}
\hline Wavelength, $\mu \mathrm{m}$ & 0.4 & 0.5 & 0.6 & 0.7 & 0.8 & 0.9 & 1.0 & 2.0 & 3.0 \\
\hline Reflectance $* \%$ & 33 & 40 & 88 & 96 & 97 & 98 & 100 & 71 & 72 \\
\hline
\end{tabular}

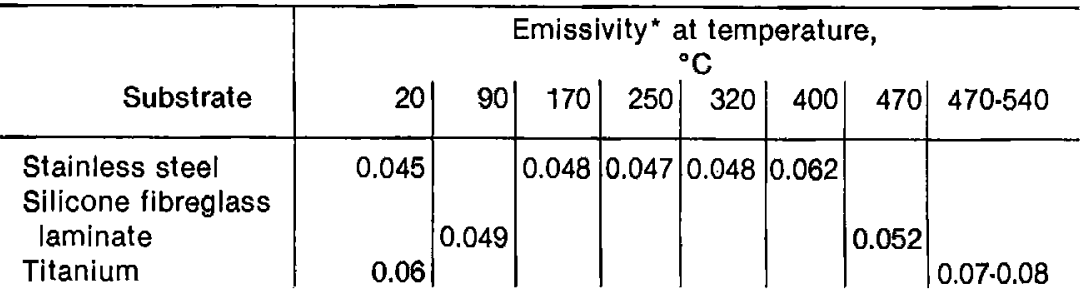

Determined with a Northrop Model 205 recording diffuse reflectometer and a Model 13.4 Universal spectrophotometer.

Measurements of the total emissivity at different temperatures of gold films obtained by the application of liquid preparations on various substrates have shown this indeed to be the case (Table II).

The full benefit of this important property of gold is obtained by applying sufficient gold on the substrate to develop fired films of thickness 100 to $125 \mathrm{~nm}$. This requires approximately $20 \mathrm{~g}$ of liquid gold to cover $1 \mathrm{~m}^{2}$ of area at a material cost of about U.S. $\$ 40$.

One aircraft manufacturer reports having achieved, by the

Fig. 7 Gold decorated glass and ceramic objects still provide an affordable means of demonstrating affluence in today's society

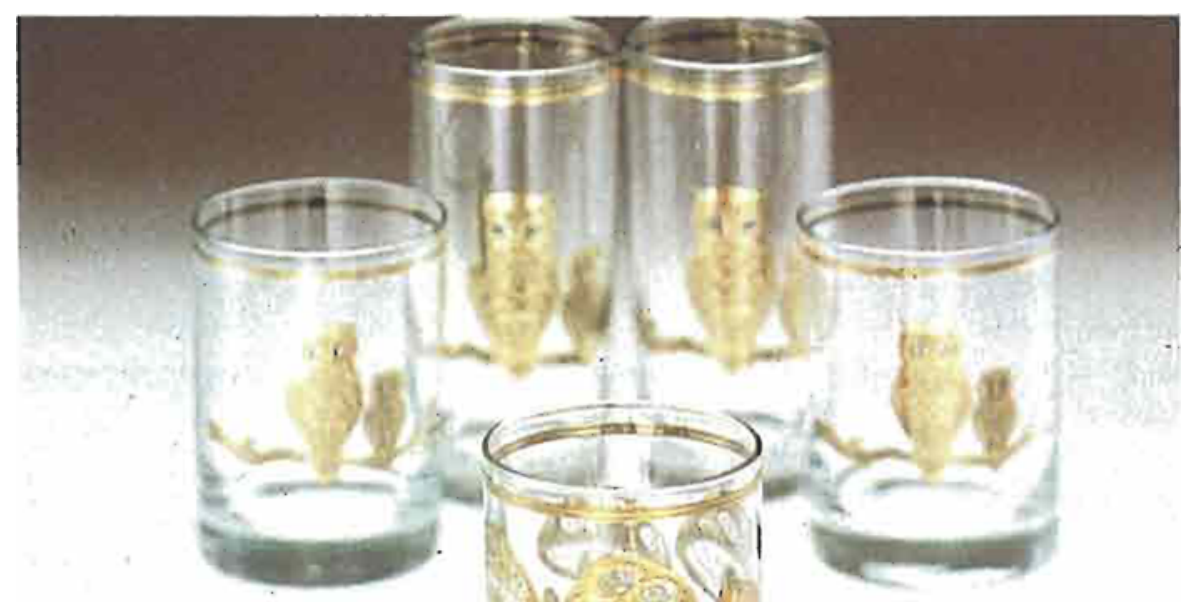


use of a gold coating on the inner and outer surfaces of a titanium tailcone fire-wall shroud, a reduction of about $165^{\circ} \mathrm{C}$ in the maximum shroud temperature which was thereby maintained at below $425^{\circ} \mathrm{C}$ on the inboard side. This reduction of temperature eliminated the need for costly structural materials in the proximity of the tailcone.

The usefulness of liquid gold for protection from the effects of solar radiation was visibly demonstrated to the world during the United States Government's Apollo 14 space mission (8). Reflective gold-coated plastic film wrapped around various parts of the lunar landing module and vehicle protected sensitive parts from solar radiation, as clearly seen by television vicwers of the event.

Another useful property of gold, its electrical conductivity, has led to a variety of functional uses within the dynamic and high-technology area of electronics. The use of gold-rich pastes is a well developed technology practised by hybrid microelectronic component manufacturers. The present state of the art requires heavier gold films than those produced from liquid golds, unless metallic gold powders are suspended in them. Nevertheless, they have found applications in electronic and electrical devices. Liquid gold coatings on the interior of ceramic cathode-ray tube bodies function as an electrical shield (9). On discrete ceramic resistor bodies they also provide electrical termination contacts, while deposits of small amounts of liquid gold serve as electrical conductors on thermal print-heads for high-speed printers.

Other interesting applications of liquid golds in the electronics industry include electrically conductive paths in photocells that automatically control street lights, and films on quartz pressure transducers. Liquid preparations of gold in combination with other precious metals are used to coat television tube components which have found applications as arc suppressants, and also as thin film resistors in electronic circuitry.

\section{Future Prospects}

Gold will continue to be an important commodity in the foreseeable future. It is assumed that society will continue to seek ways to demonstrate affluence, and gilded ceramic and glass articles have always represented an affordable means of doing so. Therefore, liquid gold should maintain its privileged position among the range of products available to decorators.

The methods of application and the nature of substrates are not expected to change dramatically in the near future. As in the past, when more stringent demands are made by users with specific needs, manufacturers will be called upon to fulfil them. Improvements will be reflected through increased durability of films, better application properties of the preparations, especially those for use in automatic decorating machines and, most importantly, lower cost products. The latter requirement is affected by increases in the price of gold, which could be critical to the viability of liquid golds if they were to be excessive. As we have mentioned above, greater gold costs have already contributed to the more selective use of liquid golds in recent years.

The electronics industry offers the best potential for growth in usage of liquid golds. Precious metal-oriented since its inception, thick film technology utilizes gold in the form of pastes comprising fine powder of less than $10 \mu \mathrm{m}$ in a vehicle suspension. Recently, however, interest has developed in films made from solutions of organic metal compounds. Studies show that thin precious metal films offer several advantages over thick film technology. Being true solutions, liquid golds and other organic metal preparations are uniform in composition. Their use eliminates the ingredient variations sometimes experienced with powder particles and possible contamination during processing of the components of thick film inks. Liquid golds are suited to a variety of application techniques which are not possible with powder suspensions and thick film inks, and they produce more uniform surfaces.

A major constraint in the use of liquid golds is their lower electrical conductivity and the sensitivity of that property to substrate surface finish. This problem must be overcome if the utilization of liquid golds for electronic applications is to increase significantly in the future. However, prospects for a solution are encouraging, based upon preliminary results from research and development projects underway.

Not all the functional uses of liquid golds have been reviewed here. Many other untapped markets exist for the products of liquid gold manufacturers. Thus, increasing exploitation of the unique properties of liquid golds in industry, for heat reflection, in optical, electrical or electronic devices, in architecture and in other uses can be expected. The basic technology is available, and the potential for wider application exists. Recognition of these facts and a commitment by industry to pursue new opportunities should ensure the continued expansion of liquid gold usage.

\section{References}

1 A.A. Milgram, J. Electrochem. Soc, 1971, 118, (2), 287-293 J.W.M. Biesterbos, J. Appl. Phys,, 1974, 45, (1), 163

2 W.S. Rapson, Gold Bull, 1979, 12, (3), 108-114

3 L.B. Hunt, Gold Bull., 1979, 12, (3), 116-127

4 'Bright Gold Guide', Degussa, Frankfurt, 1979, p. 5

5 F. Chemnitius, J. Prakt. Chem., 1927, 117, 245-261

6 K.H. Ballard (to E.I. du Pont de Nemours \& Co.), U.S. Patent 2,490,399 (1949)

7 H.M. Fitch (to Engelhard Industries), U.S. Patent 2,984,575 (1961)

8 R.C. Langley, Gold Bull., 1971, 4, (4), 62-66

9 B.O. Baker, Br. J. Appl. Phys, $1953,4,311.315$ 
Fig. 8 Liquid bright gold film acts as an electrial shield on the interior of ceramic cathode ray tubes

Fig. 9 Gold coated porcelain enamelled steel reflectors are used in office copying machines
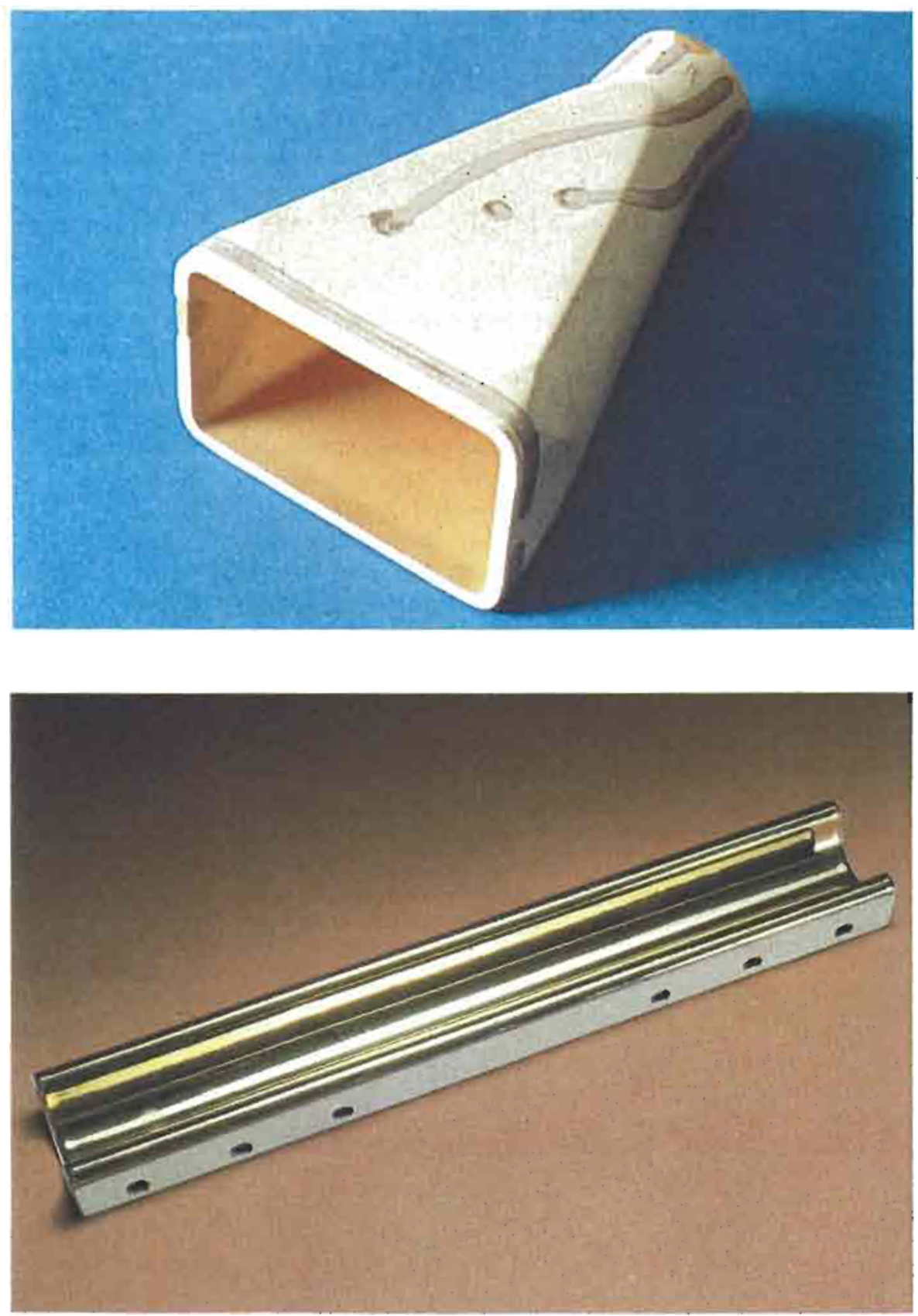